\title{
ENVIRONMENTAL REGULATIONS AND NEW PLANT LOCATION DECISIONS: EVIDENCE FROM A META-ANALYSIS*
}

\section{Tim Jeppesen}

Department of Economics, University of Southern Denmark, Odense Campus, DK-5230

Odense M, Denmark.Email:tij@sam.sdu.dk

\section{John A. List}

Department of Agricultural and Resource Economics, University of Maryland, U.S.A. E-mail:jlist@arec.umd.edu

\section{Henk Folmer}

Tilburg University, CentER and Wageningen University, Department of Economics, Hollandseweg 1, $6706 \mathrm{KN}$ Wageningen, The Netherlands. E-mail:

Henk.Folmer@alg.ech.wag-ur.nl

\begin{abstract}
Stricter environmental regulations are often opposed on the grounds that they will alter equilibrium capital flows. Empirical evidence in this area remains largely unresolved, mainly due to the quite disparate results found in the literature. This paper takes a positive look at the relationship between new manufacturing plant location decisions and environmental regulations by examining data from 11 studies that provide more than 365 observations. One major result from our meta-analysis is that methodological considerations play a critical role in shaping the body of received estimates. Our empirical estimates also lend insights into future research that is necessary before any robust conclusions can be made regarding the effects of environmental regulations on capital flows.
\end{abstract}

"We have traded the environment for jobs . . . where the environment became either totally or partially damaged, in some instances permanently. However, we have no regrets, no remorse."

-Edwin Edwards, Governor of Louisiana, 1979

\section{INTRODUCTION}

Determining the optimal institutional arrangements for pollution control remains an important unresolved public policy issue. At the crux of the debate

*We thank the three anonymous reviewers as well as the editors for thoughtful remarks. Pascal Nielsen provided valuable research assistance. Also we thank Shelby Gerking and Raymond Florax for useful suggestions. Participants at the Environment and Firm Competitiveness Conference in Kerkrade, Holland also provided useful remarks. Any errors are the sole responsibility of the authors.

Received November 2000; revised March 2001; accepted March 2001.

(C) Blackwell Publishing, Inc. 2002.

Blackwell Publishing, Inc., 350 Main Street, Malden, MA 02148, USA and 108 Cowley Road, Oxford, OX4 1JF, UK. 
is whether devolution will induce localities to "race to the bottom" in a pursuit of industry and jobs. ${ }^{1}$ If public officials are behaving broadly in accordance with Governor Edwin Edwards' quote above, allowing localities to set and enforce environmental regulations could critically undermine efficient pollution control standards. In a theoretical context, Wilson (1996), Ulph (1997), Kuhn (1998), Rauscher (1994; 1997), and List and Mason (2001), among others, present a number of scenarios under which local environmental regulations may reasonably race to the bottom. Fundamental to these theoretical models is the assumption that capital flows respond adversely to more stringent environmental regulations. Although this assumption appears innocuous, the empirical estimates in the received literature, which range from positive and significant to negative and significant, lead most to conclude that the relationship is weak at best (see, for example, Jaffe et al., 1995). ${ }^{2}$

In light of the numerous estimates in the literature, a rational policymaker could justify a myriad of institutional arrangements for the optimal control of pollution. The purpose of this paper is to bridge the gaps in the literature by examining statistically the characteristics of empirical studies to uncover the factors that influence the relationship between new firm location and environmental regulations. ${ }^{3}$ Rather than providing only a casual narrative summarizing the numerous empirical studies, we use a meta-analysis to examine if received estimates are sensitive to modeling approaches, which include such factors as estimation technique, data issues, and the accountability of various causal factors. Our study is similar in spirit to other meta-analyses, which have provided significant insights into a variety of topics, issues dealt with include air quality (Smith and Huang 1993; 1995), Ricardian equivalence (Stanley, 1998), gasoline demand (Espey, 1998), environmental Kuznets curves (Cavlovic et al., 2000), recreation benefits (Smith and Kaoru, 1990), calibration of hypothetical

${ }^{1}$ List and Gerking (2000) provide an empirical test of whether U.S. states raced to the bottom when they were given more authority to enforce pollution regulations.

${ }^{2}$ Note that stricter environmental policies could have positive effects on profits and therefore induce capital inflows if they are not fully capitalized in land rents and worker wages. For instance, environmental quality may reduce mortality and morbidity rates and provide amenity values to employees that increase worker productivity. As such, in certain circumstances environmental policy could also be a "pull" factor. The interested reader should see Goodstein (1999) and Jeppesen and Folmer (2002), who provide excellent surveys on the issue of jobs versus the environment.

${ }^{3}$ Increased environmental standards can trigger a myriad of plant-level responses. For example, existing plants could (1) continue production at the same location with modifications to the production process, for example, installation of scrubbers; (2) relocate; (3) shift production from a plant at one location to plants in other locations; or (4) exit the industry without starting up at another location. Although these are interesting phenomena in their own right, given the dearth of studies in these areas we focus our attention on the effects of environmental regulations on new plant start-ups because this is the question most often posed in the literature. This points to an area of future research because little is known about the effects of environmental regulations on plant exit rates, plant relocation, and production shifting. Accordingly, we hope that our results will aid in the development of this literature because estimation technique, data issues, and the accountability of various causal factors will undoubtedly be important for these lines of research also.

(C) Blackwell Publishing, Inc. 2002. 
or actual behavior in experimental contingent valuation markets (List and Gallet, 2000), and various transportation issues (for example, Button, 1995; Button and Kerr, 1996; van den Bergh and Button, 1997). These studies, among others, have revealed that a properly done meta-analysis has a distinct advantage of developing a consensus on point estimates by summarizing over a collection of similar relationships and indicators.

A meta-analysis is particularly appealing when considering published reports concerning the relationship between manufacturing start-ups and environmental regulations. Upon perusing the received estimates, one quickly comes to the realization that synthesizing the literature is nearly impossible because heterogeneous point estimates often are obtained using disparate modeling techniques and data. Nevertheless, an appropriate understanding of the relationship between modeling procedures and empirical estimates is invaluable to the policymaker interested in implementing optimal policies. Furthermore, given that any particular estimate may be viewed with skepticism and challenged on the basis of empirical specification, insights from a meta-analysis are very useful to researchers interested in theoretically or empirically specifying models because they highlight the degree to which empirical estimates are sensitive to slight modeling changes. Indeed, nearly two decades ago Leamer's (1983) study served to caution researchers and policymakers about the potential "con" in econometric studies when empirical results may be reversed by slight adjustments in model specification.

Our empirical insights allow us to more fully understand the effects of environmental regulations on new plant location decisions where hundreds of estimates have been published. Using more than 365 observations, we find that variables within each of our four broad categories-empirical specification, data, definition of regulatory variable, and included control variables-have a considerable influence on the coefficient estimate. In particular, we find that the smaller the geographic area of study, the larger the estimated influence of environmental regulation on new plant start-ups. Our results suggest that foreign firms investing in the U.S. are more influenced by environmental regulations than their domestic counterparts. Finally, certain empirical results shed light on shortcomings in the extant literature. In this regard, we find that the frequently reported result that pollution and nonpollution intensive industries are affected similarly by pollution regulations may be a negative repercussion of pooling industries that are heterogeneous along dimensions of footlooseness, factor inputs, lobbying-power, and of failing to note whether outputs are exported or consumed locally.

The remainder of our study is organized as follows. Section 2 presents a narrative overview of the influence of environmental regulations on capital flows. Section 3 presents the data and the empirical model. Section 4 discusses the estimation results, and the paper concludes with a summary in Section 5. 


\section{LITERATURE SURVEY}

The early 1970s marked an unprecedented increase in public awareness for the environment in the U.S. Since the original Earth Day, firm-level pollution abatement compliance expenditures have skyrocketed, mainly due to more ambitious environmental programs over time. To track the magnitude of these expenditures, the U.S. Department of Commerce has collected data on firm-level pollution abatement expenditures to abate the media air, water, and solid contained waste. The raw data are indicative of the regulatory burden that environmental regulations impose on firms-for example, in 1993 industrial pollution abatement capital expenditures amounted to 7,177 million dollars, or approximately 7 percent of new capital expenditures. However, these abatement expenditures are, distributed very unevenly across industries. To provide an indication of the magnitudes and distribution of pollution abatement expenditures we present Table 1, which contains pollution abatement and control expenditures (PACE) for selected industries in the U.S. from 1990-1994. The figures show the substantial investment that current regulations induce certain industries to undertake. For example, in 1993, pollution abatement capital expenditures in the petroleum and coal products industry totalled 2,649 million dollars, or 42 percent of the total capital expenditures in that year.

Although the figures in Table 1 are relatively large, the nature and extent to which these pollution abatement expenditures induce plants to locate in low stringency areas remains an empirical question. Not surprisingly, numerous studies have examined the impact of environmental policy on new plant location decisions. Empirical papers examining the relationship between environmental regulations and manufacturing activity can be divided into two waves. Studies in the first wave include Bartik, (1988; 1989), McConnell and Schwab (1990),

TABLE 1: Pollution Abatement and Control Expenditures for Selected Industries in the U.S. ${ }^{a, b}$

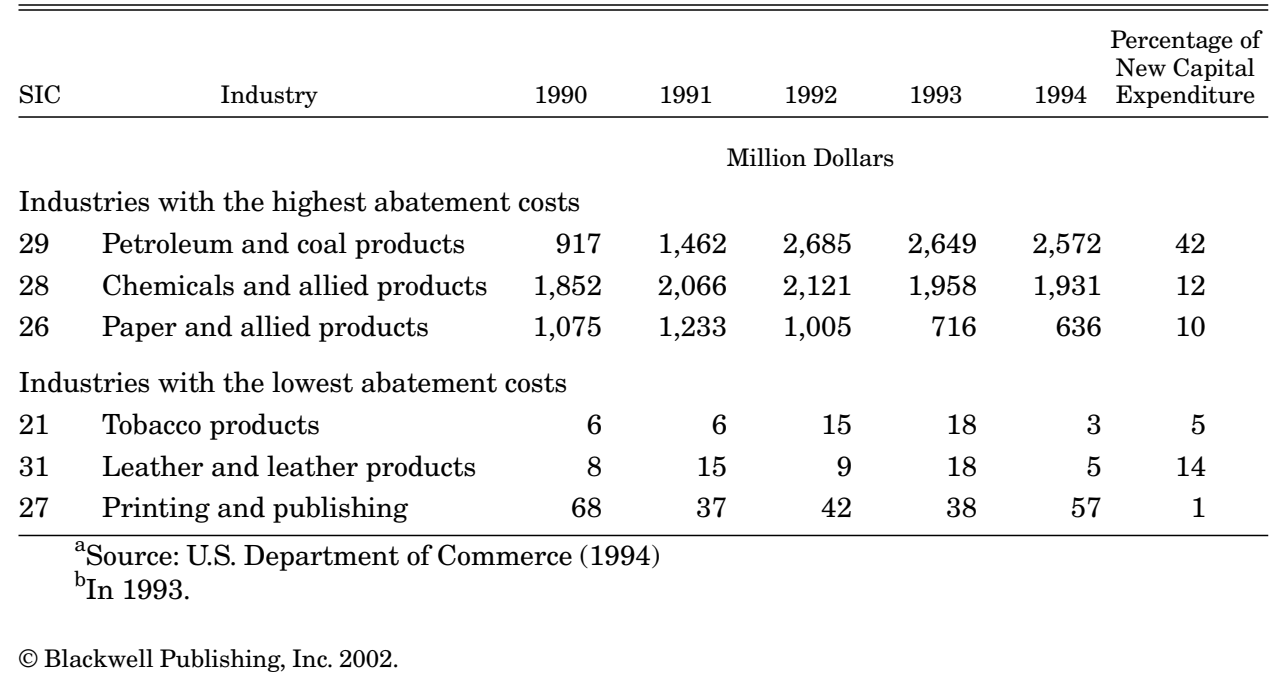


Duffy-Deno (1992), Friedman, Gerlowski, and Silberman (1992), and Levinson (1996), among others. These papers find little systematic evidence in support of the hypothesis that environmental regulations affect capital location decisions. Coefficients of the environmental regulation variable are often found to be insignificant and some are even positive, suggesting that if the regression equation is specified correctly the "pull effect" of more stringent environmental regulations dominates the "push effect". Moreover, even when negative coefficients are found, they are typically quite small. For example, Levinson (1996) examines the effects of six different measures of environmental regulation on the probability that a new plant will locate in a given state. Only two of the state-level variables measuring environmental regulation are significant and negative. Equally as important, he finds that a one standard deviation increase in the measure of environmental regulation (approximately a 95 percent increase) reduces the probability that a firm will locate in a state with average characteristics by 1.5 percent.

McConnell and Schwab (1990) examine the influence of environmental regulations on the location decisions of new branch plants in the automobile industry. Eight of their nine measures of environmental policy stringency had small and insignificant effects on plant location decisions. Inference from the significant and negative coefficient suggests that an increase in the environmental policy variable by 20 percent reduces the probability of new plant location from initially 0.4 percent to approximately 0.1 percent. The coefficient on the environmental regulation variable in Bartik (1989) is also significant and negative, but tiny - a one standard deviation increase in the policy variable is found to reduce the start-up rate of small businesses by 0.01 standard deviations. Partly based on these studies, review articles have concluded that stricter environmental regulations do not consistently influence the location of industrial activity (Jaffe et al., 1995; Tannenwald, 1997; and Gerking and List, 2001).

Papers in the second research wave include, but are not limited to, Becker and Henderson (2000), Gray (1997), Henderson (1996; 1997), Kahn (1997), Keller and Levinson (1999), and List et al. (1999). These studies typically find much stronger evidence in favor of the hypothesis that environmental regulations affect the allocation of new firms. Coefficients of the environmental regulation variables are often significant and negative, and the effects are much larger in absolute value than the effects presented in the first wave of studies. For instance, in Henderson (1996) the two measures of environmental regulations are significant and negative in seven out of nine regression models. Furthermore, estimated effects are relatively large: counties switching from attainment status to nonattainment status experience large decreases in plant stocks. In addition, Henderson (1997) finds that the level of environmental regulation is significant and negatively influences firms in seven out of ten regression models. Furthermore, the estimated effects are quite large-if a county moves to "in attainment" from "out-of-attainment" then the probability that a new plant will choose to locate in that county increases from 0.25 to anywhere between 0.39-0.71. In List et al. (1999), the environmental regulation measure has a 
negative and significant effect in only 2 of the 12 regression specifications, but the measured effects are quite large. When a county is labeled out-of-attainment, its flow of new firm births decreases by almost 90 percent.

Clearly, studies in the second wave of research typically find more evidence that capital flows respond to heterogeneous environmental regulations. Why this occurs is not entirely clear. One possible conjecture is that the second generation studies have refined the analysis in a number of meaningful ways: (i) papers in the first wave are typically aggregated studies relying on crosssectional data and estimation methods; (ii) studies in the first wave usually use aggregate measures of economic activity or analyze micro-data at the state or national level; (iii) studies in the first wave use data that covers the time period from the early 1970s to the late 1980s; and (iv) studies in the second wave focus attention on the most polluting industries and use a number of different estimation techniques.

Although these methodological differences between first and second wave studies could potentially explain the difference in results, a confounding variables problem exists in pinpointing the exact explanation because numerous important differences exist both between studies in each wave as well as between studies within each wave. For example, most studies use a number of different estimation procedures and there is no agreement as to how the stringency of environmental regulations should be measured. As such, casual perusal of the reported estimates can only provide a sense of the nature and magnitude of the results; to discern between the various explanations a well-specified econometric model is needed.

\section{EMPIRICAL MODEL}

The empirical portion of this paper is based on econometric results reported in the literature concerning the effects of environmental regulations on new manufacturing location decisions. In sum, we have gathered data from 11 studies that provide 368 observations. ${ }^{4}$ All of the studies have been produced in the past two decades and use data within the time period 1963-1994. To provide a sense of the important characteristics of each study, we present a review in the Appendix, and a brief description of each study in Table 2.

The 11 papers have used many different estimation techniques to examine the impact of environmental regulations on new firm location. In some studies, regression coefficients are presented, and in others elasticities are reported. In order to compare parameter estimates across studies, it is necessary that the unit of observation is equivalent. Therefore, we calculated the corresponding elasticities computed at the sample mean in those studies that do not report elasticity estimates. Given that the typical study cited in Table 1 provides

\footnotetext{
${ }^{4}$ Note that some studies were excluded because they did not examine firm location (e.g., Henderson, 1996; Duffy-Deno, 1992; List and Kunce, 2000), or they failed to present enough estimates to pass the rank condition.

(C) Blackwell Publishing, Inc. 2002.
} 
TABLE 2: Summary of the Papers Included in the Meta-Analysis

\begin{tabular}{|c|c|c|c|c|}
\hline Article & Dependent Variable & $\begin{array}{l}\text { Time Period } \\
\text { Analyzed }\end{array}$ & $\begin{array}{l}\text { Environmental } \\
\text { Stringency } \\
\text { Measures }\end{array}$ & $\begin{array}{l}\text { Estimation } \\
\text { Procedure }\end{array}$ \\
\hline Bartik (1988) & New branch plant location & $1972-1978$ & 6 & Conditional logit \\
\hline $\begin{array}{l}\text { Becker and Henderson } \\
(2000)\end{array}$ & Firm births & 1963-1992 & 1 & $\begin{array}{l}\text { Conditional Poisson, } \\
\text { Fixed effects }\end{array}$ \\
\hline $\begin{array}{l}\text { Friedman Gerlowski, } \\
\text { and Silberman (1992) }\end{array}$ & $\begin{array}{l}\text { Foreign new branch plant } \\
\text { location }\end{array}$ & $1977-1988$ & 1 & Conditional logit \\
\hline Gray (1997) & $\begin{array}{l}\text { New plant birth rates, } \\
\text { Numbers of new plants }\end{array}$ & $1963-1989$ & 7 & $\begin{array}{l}\text { OLS, Fixed effects, } \\
\text { Random effects, } \\
\text { Conditional logit, } \\
\text { Poisson }\end{array}$ \\
\hline Henderson (1997) & Number of plants & $1977-1987$ & 2 & $\begin{array}{l}\text { Logit, Chamberlain } \\
\text { logit }\end{array}$ \\
\hline $\begin{array}{l}\text { Keller and Levinson } \\
\text { (1999) }\end{array}$ & Inflow of FDI, New plants & 1977-1994 & 3 & $\begin{array}{l}\text { OLS, Fixed effects, } \\
\text { Pooled Poisson, Fixed } \\
\text { effects Poisson, GMM }\end{array}$ \\
\hline Levinson (1996) & New plant location & $1982-1987$ & 6 & Conditional logit \\
\hline List (2001) & Number of FDI new plants & 1983-1992 & 1 & Poisson \\
\hline List and Co (2000) & Number of FDI new plants & 1986-1993 & 3 & Conditional logit \\
\hline List et al. (1999) & Firm births & $1980-1990$ & 1 & Poisson \\
\hline $\begin{array}{l}\text { McConnell and Schwab } \\
(1990)\end{array}$ & New plant location & 1973-1982 & 9 & Conditional logit \\
\hline
\end{tabular}

numerous empirical estimates concerning the effects of environmental regulations on firm location, we view the data to be panel in nature; for example, because List and Co (2000) examine four distinct stringency measures across three different industry groupings, their study provides 12 elasticity estimates. ${ }^{5}$ Therefore, we use our meta-data to estimate variants of the following unbalanced panel data model

$$
E_{i j}=\alpha_{i}+\beta X_{i j}+e_{i j}
$$

where $E_{\mathrm{ij}}$ denotes study $i$ 's $j$ th elasticity estimate of the effect of environmental regulations on firm location, and $\alpha_{i}$ represents a 'random researcher' effect that controls for individual specific effects that may affect reported empirical estimates. The random effects provide a control for the commonality within a study, and control for the dependence of observations within each paper. The response

\footnotetext{
${ }^{5}$ When statistically examining the data, many meta-analyses ignore the dependence of observations across and within studies. This particular aspect of the literature is unfortunate, because inappropriate estimates may result if the panel nature of the data is not recognized. Note that when studies use two environmental regressors in one specification (one regression model) we treat the coefficients of the two regressors as two individual observations.
} 
coefficients $\beta$ and the factors $X_{i j}$ are presumed to affect the reported elasticity. The $e_{i j}$ are i.i.d. error terms with zero mean and constant variance $\sigma_{e}^{2}$; and $E\left[\alpha_{i}\right]=0, E\left[\alpha_{i}^{2}\right]=\sigma_{\alpha}^{2}, E\left[\alpha_{i} \alpha_{v}\right]=0$ for $i \neq v, \alpha_{i}$ and $e_{i j}$, are orthogonal for all $i$ and $j$.

Before proceeding, a few aspects of our estimation procedure are worthy of brief comment. First, given that we treat unmeasured characteristics $\alpha_{i}$ as error components, our estimation procedure is generalized least-squares, which economizes on degrees of freedom, yields coefficients that are not conditioned on unmeasured researcher effects, and draws the $\alpha_{i}$ from a Gaussian distribution. Note that we could also control for unobservables by using a least-squares dummy-variable (fixed-effects) approach, whereby unmeasured researcher effects are shifts in the constant term; hence, estimates of the marginal effects of $X$ on $E$ are conditioned on the unmeasured characteristics. We opt for the random effects approach rather than a fixed-effects model for two main reasons: (1) when researchers report numerous parameter estimates in a study, they typically use very similar regression models to derive these estimates, hence there is no variation in important variables, making our primary hypotheses untestable in a fixed-effects framework because any static regressors are swept away by the fixed effects; and (2) because estimates from fixed- and randomeffects models converge when the number of cross-sectional units and the length of the time series expand, our random-effects estimates are preferred as they are more efficient than fixed-effects estimates.

Second, we supplement these baseline estimates with empirical results from two alternative models, namely ordinary least-squares (OLS) and a group means regression (GM). The OLS model results if the variance of the individual effects is not different from zero in the random-effects panel data model. The GM model expresses the data in 'researcher' means-for example, $E_{i j}\left(X_{i j}\right)$ is replaced with $E_{i}=J^{-1} \Sigma_{j} E_{i j}\left(X_{i}=J^{-1} \Sigma_{j} X_{i j}\right)$. This particular regression model is considered a between-estimator because the $\beta$ are estimated based on crossstudy variation only. The GM regression model is analogous to a typical crosssectional estimation procedure, but in our panel data model GM regression is typically inefficient because important information is lost in the grouping process.

We complement these regression estimates with a limited dependent variable model that investigates factors that determine whether the estimated elasticity has the correct sign and is significantly different from zero at conventional levels. The estimated model is given by

$$
S_{i j}=\beta Z_{i j}+e_{i j}
$$

where $S_{i j}$ denotes whether study $i$ 's $j$ th elasticity estimate is significantly different from zero at the $p<0.05$ level and has the correct sign. If the correct sign is significantly negative at the $p<.05$ level, then $S_{i j}=1$, otherwise $S_{i j}=0$. $\beta$ are estimated response coefficients; $Z_{i j}$ is identical to $X_{i j}$ in Equation (1), but 
also includes a measure of the sample size; $e_{i j}$ are i.i.d. error terms with zero mean and constant variance $\sigma_{e}^{2}$.

\section{Explanatory Variables}

In this subsection we describe the explanatory variables of Equations (1) and (2) that have been identified on the basis of a systematic comparison of the above-mentioned studies. We should note that other regressors could have been included also, but given that our focus pertains to important methodological protocol, we chose to examine the design parameters reported in the majority of published studies. This procedure allows a much broader analysis while not compromising the generality of our results significantly. Briefly, the relevant variables are as follows:

Researcher-Specific Effects. Given that we are afforded the opportunity to examine multiple observations within each study, the $\alpha_{i}$ in the estimated equations represent a 'random researcher' effect, which by definition controls for individual specific effects that may affect reported empirical estimates. The random effects could potentially reveal interesting insights, because they provide a control for the commonality within a study and control for the dependence of observations within each paper. In addition they relate to such issues as selection of the data, treatment of outliers, publication habits, the regression approach, and so on. For example, if a specific researcher tends to publish estimates that are not in line with other studies, ceteris paribus, one could conclude that important unobservable influences exist among researchers, and therefore, an explanation of the anomalous results in the literature would be transparent.

Cross-Section Versus Panel-Data Techniques. From a methodological point of view, panel-data regression techniques are preferable to cross-sectional regression models because the former attempt to control for the correct specification of the causal relationship between location and environmental policy. For example, an influx of polluting firms into a region could induce an increase in the stringency of environmental policy, which potentially affects future firm location behavior. The specific nature of this dynamic causal relationship should ideally be modeled explicitly; that is, the relationship between firm births and stringency of environmental policy is most accurately modeled sequentially rather than simultaneously. If the sequential ordering is ignored, and if firm births and environmental policy are modeled as occurring simultaneously, a spurious positive relationship could be observed. This would be the case if the data relate to the first part of the causal chain relating to an influx of polluting firms and an increase of the stringency of environmental policy. Alternatively, if the data relate to the second part of the causal chain (characterized by stringent environmental policy and a possible decrease of new firm locations), then the regression model would yield a negative effect of environmental policy on new firm location decisions. Adequate representation of the causal relationship requires a model specification in which environmental policy at time $t$ is a 
function of firm births at time $t-p, t-p-1, t-p-2, \ldots, t-p-k$ and firm births at time $t+q$ are a function of environmental policy in period $t, t-1, t-2, \ldots$, $t-z$.

Panel-data regression techniques also allow the researcher to control for important unobservable variables that are time-invariant, such as historical and structural factors, land area, distance between trading partners, and other factors that are static over the sample period. Relatedly, use of panel-data techniques largely alleviates the omitted variables problem-observations on some systematic nonpolicy location factors are often missing from crosssectional specifications. This may lead to the deletion of those variables for which observations are unavailable or the use of proxies and, consequently, to the econometric problems associated with missing variables and proxies. In particular, if an omitted site characteristic correlates with a policy variable, the estimated coefficient of the policy variable as well as its estimated variance will be biased and proper inference will be impossible.

As highlighted in Table 3, this particular variable can take on one of three states: (i) panel treatment, (ii) panel data/cross-section treatment (panel data but treated as cross-sectional), or (iii) cross-sectional data. Panel treatment denotes those estimates that are derived from regression models using panel data, and treated as such. Panel data/cross-section treatment denotes those

TABLE 3: Variable Definitions

\begin{tabular}{ll}
\hline \hline Variable & \multicolumn{1}{c}{ Categories } \\
\hline Treatment of Time & $\begin{array}{l}\text { Panel Treatment } \\
\text { Panel Data/Cross-section Treatment } \\
\text { (panel data but treated as cross-sectional) } \\
\text { Cross-sectional Data (reference group) }\end{array}$ \\
& Pooled Pollution Intensive/ Non-Pollution intensive \\
Aggregation & Dirty Industries (reference group) \\
Time Period & Post -1980 Data \\
& Otherwise (reference group) \\
Geographical Coverage & Foreign entrants \\
& Domestic entrants (reference group) \\
Definition of Stringency of & Private expenditures \\
Environmental Policy & Public expenditures \\
& County attainment status (reference group) \\
Wage & Wages included \\
Agglomeration & Otherwise (reference group) \\
& Agglomeration effects included \\
& Otherwise (reference group) \\
& Taxes included \\
& Otherwise (reference group) \\
\end{tabular}


estimates that are obtained from regression models using panel data, but that do not control for unobservables (least-squares was applied to the pooled data). Cross-sectional refers to those estimates that were obtained from regression models using purely cross-sectional data and empirical methods.

Level of Aggregation. Many studies pool data across industries of varying pollution intensity due to data constraints. This implies that the effects of more stringent pollution regulations are restricted to be isomorphic across clean and dirty sectors-the "one size fits all" approach. Therefore, ceteris paribus, the estimated regulatory effect is an average that is an over-estimate of the true effect for plants in the clean sectors and an under-estimate for the dirty sectors. From a methodological point of view this implies that sectoral aggregation is questionable. Of particular importance is whether there is a distinction between clean and dirty industries. We divide the studies along these dimensions to provide a sense of how aggregation influences reported estimates.

Time Period. Another potentially important aspect of the received estimates relates to the time period analyzed. Growing awareness and better knowledge of environmental problems has gradually led to an increase in stringency of environmental policy. For instance, real pollution control expenditures in the U.S. have increased by more than 100 percent from 1972-1982. Ceteris paribus, this implies that studies using data from earlier time periods should find much smaller effects compared to studies relying on data from later time periods. Moreover, concerning the U.S., the period before 1978 was one of much state-level confusion in implementing and carrying out environmental regulations mandated in the 1970 Clean Air Act Amendments (see for example List, 2001; Becker and Henderson, 2000), perhaps leading to few strictly monitored sites.

Definition of Environmental Policy. Stringency of environmental policy relates to the restrictions that a regulator imposes on polluters by means of such measures as product norms, regulations, and emission charges. If effective, these sorts of policies could lead to an increase in production costs. Studies in the literature differ widely in terms of measurement of environmental regulation. To operationalize these various measures, we group the various definitions into three subcategories:

(1) Private pollution abatement efforts. Examples include additional investment costs (e.g., because of the installation of scrubbers) or additional environmental tax payments.

(2) Indexes of public regulatory stringency as reflected by the public authorities' statutes and their ability or efforts to enforce these statutes. Examples of the public authorities' statutes are the Conservation Index, the FREE Index, and the Green Index. See Levinson (1996) for definitions and further references. Examples of the public authorities' ability and effort to enforce their statutes are monitoring expenditures or number of persons employed in implementation and monitoring activities.

(3) County-level attainment status, defined as whether or not a county is in attainment of national environmental air quality standards. Counties not 
in attainment of federal standards for the various air pollutant types are subject to specific restrictions that are not faced by counties that attain federal standards. Moreover, new firms are subject to more stringent regulations than existing firms. New polluting plants locating in a nonattainment county are subject to a standard of Lowest Achievable Emission Rate (LAER), requiring the cleanest existing technology, regardless of cost. New plants in attainment counties are required to install Best Available Control Technology (BACT). BACT is negotiated case-by-case, where the economic burden on the plant is taken into consideration. BACT is much less costly than installation of LAER in nonattainment counties.

Geographic Coverage. A basic finding from the public finance literature is that the smaller the area of study, the larger the influence of effective tax rates. For example, intraregional studies typically present tax elasticities that are at least four times greater than estimated interregional tax elasticities (Wasylenko, 1997). The intuition behind this finding is that smaller areas tend to have less variation in other important location factors, such as labor markets, climate, and energy costs, which in turn accentuates any differences in tax packages. Due to data coverage-counties only have attainment status as an environmental regulatory measure whereas states do not have attainment status as a stringency measure-our estimation procedure will proceed by combining geographic coverage with the environmental measures, and therefore we examine simultaneously if county and attainment status measures affect the reported results in the literature.

Other Controls. In our meta-regression analysis, we also examine numerous other methodological issues in the literature. Given that some studies use domestic (U.S.) data, whereas others focus on foreign entrants, we have a natural variation to provide evidence on the relative effects of environmental regulations across foreign and domestic entrants. In addition, because some studies account for regional characteristics, such as the tax and wage rates and agglomeration effects whereas others do not, we can examine whether omission of systematic variables affects the sign and magnitude of the environmental policy measure.

An overview of the explanatory variables in $X_{i j}$ and their definitions are given in Table 3. Roughly, we can split the regressor vector into four broad categories: (i) empirical specification; (ii) data (including level of aggregation) time-frame, and foreign versus domestically owned capital; (iii) environmental regulatory variable; and (iv) other control variables, including whether wage, agglomeration, or tax measures were included in the estimated regression.

\section{EMPIRICAL RESULTS}

Table 4 contains our panel data estimation results for Equation (1). Each column in the table contains a distinct model as discussed above. In the case of the random effects models, a statistical test of the hypothesis $\sigma_{\alpha}^{2}=0$, leads us to not reject the null hypothesis at even the $p=0.35$ level using a LaGrange Multiplier test, $\chi^{2}(1$ d.f. $)=0.81$, implying that researcher-specific factors are 
TABLE 4: Empirical Estimates of Elasticity Equation ${ }^{\mathrm{a}, \mathrm{b}}$

\begin{tabular}{llcc}
\hline \hline Category & Variable & OLS & Model Type \\
\hline Empirical Specification & & & \\
& Panel Treatment & $-0.36^{*}$ & $-0.25^{*}$ \\
& & $(0.17)$ & $(0.10)$ \\
& Panel Data/Cross- & $-0.49^{*}$ & 0.02 \\
& Sectional Treatment & $(0.16)$ & $(0.08)$
\end{tabular}

Data

$\begin{array}{lcc}\text { Pooled Pollution Intensive/ } & -0.06 & 0.24^{*} \\ \text { Non-Pollution Intensive } & (0.07) & (0.10) \\ \text { Post-1980 } & 0.23 & 0.02 \\ & (0.15) & (0.04) \\ \text { FDI } & -0.25 & -0.23^{*} \\ & (0.19) & (0.07)\end{array}$

Regulatory Variable

$\begin{array}{lcc}\text { Private Expenditures } & 0.09 & -0.16^{*} \\ & (0.21) & (0.05) \\ \text { Public (State) Expenditures } & -0.20 & 0.07 \\ & (0.22) & (0.08)\end{array}$

Control Variables

$\begin{array}{lc}\text { Wage } & -0.47 \\ & (0.33) \\ \text { Agglomeration } & -0.03 \\ & (0.13) \\ \text { Tax } & 0.23 \\ & (0.25)\end{array}$

0.23

$\mathrm{F}(10,357)=3.91 *$

$\mathrm{F}(7,3)=27.95^{*}$

Model Test (degrees of freedom)

(10, detected.

${ }^{\mathrm{b}}$ Parameter estimates are obtained from variants of the following equation

$$
E_{i j}=\alpha_{i}+\beta X_{i j}+e_{i j}
$$

where $E_{i j}$ denotes study $i$ 's $j$ th elasticity estimate of the effect of environmental regulations on firm location; $\alpha_{i}$ represents a 'random researcher' effect that controls for individual specific effects that may affect reported empirical estimates. The $\beta$ s are response coefficients and the $X_{i j}$ are factors presumed to affect the reported elasticity.

insignificant, and for this particular set of data they do not need to be controlled in the regression model. This is an important finding because it suggests that researchers in this literature are not conducting research in a manner fundamentally different from one another. Accordingly, we suppress the randomeffects estimates and focus attention on results from the OLS and GM regression models. Other diagnostic statistics suggest that our regression models perform 
quite well, as each of the model types has a degree of predictive power witnessed by the regression diagnostics, which indicate that each model is significant at the $p<0.01$ level (OLS: $\mathrm{R}^{2}=0.10, \mathrm{~F}=3.91$; $\mathrm{GM}: \mathrm{R}^{2}=0.98, \mathrm{~F}=27.95$ ). Before proceeding, we should note that we place our discussion of empirical results in a framework where negative coefficient estimates indicate that the variable induces evidence of a pollution haven effect, and a positive numerical estimate suggests the opposite. Furthermore, it is interesting to note that the mean elasticity estimate reported in the literature is -0.28 , implying that on average a slight pollution haven effect is evident.

Given that the estimates across our two major model types-Equations (1) and (2)—are linked, we present regression results from Equation (2) in Table 5 and discuss the overall results simultaneously. Before commencing the discussion of parameter estimates, we note two important aspects of the estimation procedure in Equation (2). First, both the linear probability model and the probit model are significant at conventional levels ( $\mathrm{F}=5.47, \mathrm{LPM} ; \chi^{2}=71.1$, probit). Second, a positive coefficient estimate in Table 5 implies that the probability of significance increases with increases in the particular variable. Hence, although the comparison across Equations (1) and (2) is not perfect because significance is a function of two parameters, point estimates and standard errors, whereas magnitude is a function of one, roughly a negative coefficient in Table 4 and a positive coefficient in Table 5 are consistent in the sense of unambiguously producing evidence in favor of the pollution haven effect. Finally, we should note that approximately 35 percent of the documented estimates in the literature reveal that the coefficient of the environmental measure is negative and significant at the $p<0.05$ level.

Variables within each of our four broad categories are significantly different from zero at conventional levels in both major model types. Specifically, in Table 4 we find that coefficient estimates of panel treatment are negative, suggesting the baseline of relying on purely between-unit variation (cross- sectional regression model) produces less evidence of a pollution haven effect than use of a panel-data model. This result implies that, conditional on other regressors, one will tend to find more evidence of a pollution haven effect when panel data methods are used. Empirical results are largely consistent across Equations (1) and (2), as we observe similar insights from Table 5-panel treatment strongly improves the significance of the estimate relative to cross-sectional data. This result implies that exploiting the variability over time in regional attributes-examining the difference between new plant births in region $i$ at time $t$ and new plant births in region $i$ at time $t+\phi$ as a function of the difference in region $i$ 's regressors over this same time period-provides significantly different point estimates than a cross-sectional model that relies on purely between-unit variation.

This result typically applies to panel data that are pooled and treated in a cross-sectional regression model-a negative coefficient estimate of panel data/cross-sectional treatment implies that estimates from these models tend 
TABLE 5: Empirical Estimates of Probit Significance Equation ${ }^{\mathrm{a}, \mathrm{b}}$

\begin{tabular}{llcc}
\hline \hline Category & Variable & LPM & Model Type \\
& & & Probit \\
\hline Empirical Specification & & & \\
& Panel Treatment & $0.77^{*}$ & $1.22^{*}$ \\
& & $(0.14)$ & $(0.22)$ \\
& Panel Data/Cross- & $0.84^{*}$ & $1.28^{*}$ \\
& Sectional Treatment & $(0.13)$ & $(0.21)$
\end{tabular}

Data

$\begin{array}{lcc}\text { Pooled Pollution Intensive/ } & 0.26^{*} & 0.26^{*} \\ \text { Non-Pollution Intensive } & (0.07) & (0.07) \\ \text { Post } 1980 & 0.12 & 0.37^{*} \\ & (0.12) & (0.16) \\ \text { FDI } & 0.69^{*} & 0.85^{*} \\ & (0.18) & (0.22) \\ \text { Sample Size } & 0.28 \mathrm{E}-5^{*} & 0.30 \mathrm{E}-5^{*} \\ & (0.10 \mathrm{E}-5) & (0.11 \mathrm{E}-5)\end{array}$

Regulatory Variable

$\begin{array}{lcc}\text { Private Expenditures } & -0.90^{*} & -2.36^{*} \\ & (0.30) & (0.47) \\ \text { Public (State) Expenditures } & -0.85^{*} & -2.28^{*} \\ & (0.28) & (0.44)\end{array}$

Control Variables

$\begin{array}{lcc}\text { Wage } & -0.68^{*} & -1.79^{*} \\ & (0.24) & (0.34) \\ \text { Agglomeration } & 0.35^{*} & 0.50^{*} \\ & (0.11) & (0.14) \\ \text { Tax } & -0.24 & -0.35 \\ & (0.24) & (0.27) \\ \text { dom }) & \mathrm{F}(11,232)=5.47^{*} & \chi^{2}(1)=71.1^{*}\end{array}$

Model Test (degrees of freedom)

$$
\mathrm{F}(11,232)=5.47^{*} \quad \chi^{2}(1)=71.1^{*}
$$

\footnotetext{
${ }^{a}$ Standard errors are in parentheses below parameter estimates. Serial correlation was not detected.

${ }^{\mathrm{b}}$ Parameter estimates are obtained from variants of the following equation:

$$
S_{i j}=\beta Z_{i j}+e_{i j}
$$

where $S_{i j}$ denotes whether study $i$ 's $j$ th elasticity estimate is significantly different from zero at the $p<0.05$ level and had the correct sign. If the correct sign is significantly negative at the $p<0.05$ level, then $S_{i j}=1$, otherwise $S_{i j}=0$. The $\beta$ s are estimated response coefficients; $Z_{i j}$ is identical to $X_{i j}$ in Equation (1), but also includes a measure of the sample size.
}

to be much lower (more negative) than estimates derived from purely cross-sectional models. Comparing coefficient estimates of panel treatment and panel data/cross-section treatment in Tables 4 and 5, we find that if a researcher has 
panel data and does not treat it as such, the regulatory estimates derived will be slightly more in favor of a pollution haven effect. Overall, these estimates imply that studies using panel data, but treating the data in a cross-sectional manner, tend to provide estimates that are most in favor of the pollution haven hypothesis. These results suggest that studies leaving unobservables uncontrolled in the regression model will produce parameter estimates that potentially overstate the importance of environmental regulations. These findings represent the common heterogeneity bias argument that lends credence to a fixed- or random-effects formulation instead of simply pooling the data and estimating OLS regression.

Concerning general data issues, we find that pooling pollution intensive and nonpollution intensive industries has a weak positive influence on the elasticity estimate. Although the pooling coefficient is insignificant in the OLS model, it is positive and significant in the GM model, suggesting that studies pooling pollution intensive and nonpollution intensive industries find less evidence for the pollution haven hypothesis than studies that examine purely "dirty" industries. However, results in Table 5 suggest that pooling leads to more significant negative estimates, which is contrary to expectations and inconsistent with the GM estimate in Table 4. This anomaly provides us with our first call for future research. Although there are several possible explanations for this unexpected finding, arguments based on firm-level footlooseness, terms-of-trade effects, location of factor inputs, and industry lobbying-power are each potential factors that should be analyzed in future studies. For example, it may be the case that previous studies have incorrectly pooled data across industries that vary in their ability to move once located. In addition, if large firms in a particular industry locate in a region and the region becomes a net exporter, what we have learned from the tax incidence literature is that the stringency of pollution regulations will increase in an attempt to shift the tax burden of providing environmental quality to outside residents. Similar arguments can be made along the lines of industry lobbying-power and location of factor inputs. If any of these factors induce differential responses to increased standards across various sectors, then studies that examine groups of industries run the risk of presenting biased estimates.

Concerning the use of post 1980 data, we find positive, though insignificant effects in both regression models in Table 4. Our ex ante intuition was that later data periods would provide more evidence of pollution haven effects than earlier periods because compliance with important environmental regulations has become more costly over time, but this is not revealed through the estimation of Equation (1). However, this effect is borne out in the parameter estimates presented in Table 5. In the probit model, the parameter estimate of 0.37 is significant at the $p<0.05$ level and suggests that studies using post 1980 data tend to find more significant negative results than studies using earlier data.

Across both equations, we find that foreign firms investing in the U.S. are influenced by environmental regulations to a greater extent than their domestic counterparts. These results could be due to three interrelated aspects 
of pollution control in the U.S. First, U.S. standards and regulatory prescriptions differ substantially from those in foreign countries, forcing foreign firms to undertake substantial reengineering of their production processes to incorporate the pollution abatement capital equipment and procedures that is mandated. Second, it could be that regulators are more keenly aware of the emission rates of plants that exceed certain thresholds; ceteris paribus, assuming that larger facilities tend to generate more pollutants than smaller facilities, new foreign plants will be subject to more regulatory attention because on average they are much larger than new domestic plants. Howenstine and Zeile (1994) combine Bureau of Economic Analysis enterprise data and U.S. Census establishment data and find that foreign-owned establishments tend to have larger plants in comparison to U.S.-owned firms. Third, regulatory oversight may favor "domestic" firms relative to foreign entrants as the result of internal political pressure. Although these explanations are merely conjectures, they each represent fruitful areas for future research.

With respect to the definition of environmental stringency, we first note that the baseline category is attainment status (e.g., county-level data). We find that private measures of environmental stringency have a weak negative influence on the reported elasticity estimate. Although the coefficient of the private measure is insignificant in the OLS model, it is negative and significant in the GM model, suggesting that studies using private measures find more evidence for the pollution haven hypothesis compared with county-level studies. Coefficients of public stringency are insignificant in both models in Table 4 . Table 5 provides evidence that indicates studies using either private or public measures find less significant estimates than studies using county-level attainment status data. The fact that attainment status yields more significant negative results than other studies may be due to different geographic coverage. As mentioned previously, all studies using attainment status as the environmental measure are at the county level, and all studies using private or public stringency measures are at higher aggregation levels. Hence, generally our findings are in line with previous results published in the tax competition literature: the smaller the area of study, the larger the influence of environmental policy.

Other parameter estimates achieve sporadic significance. For example, large sample sizes lead to more significant parameter estimates (Table 5); intuition for this result follows from standard parametric hypothesis testing constructs. The effect of including other control variables is relatively heterogeneous-Table 4 shows that none of the control variables has a significant influence on the reported elasticities. However, results in Table 5 indicate that inclusion of a control for wages leads to less significant negative coefficients. Inclusion of a control variable for tax rates, which includes property taxes, corporate income taxes, business taxes, state taxes, and so on, has a similar sign but is insignificant. Inclusion of an agglomeration variable, which pertains to whether scale factors such as existing plants and manufacturing employment are included in the equation, produces evidence in favor of the pollution haven effect. These results broadly support Leamer's (1983) claim, and reveal that 
choice of the regressor vector can significantly influence the nature of the estimated regression.

\section{CONCLUDING REMARKS}

Reaching appropriate conclusions about the relationship between capital flows and environmental regulations from the published academic literature is important for researchers and policymakers. The task appears straightforward until one considers that important public policies usually are studied by a plethora of researchers, each with unique insights and techniques to solve the problem at hand. The classic example of this inextricable link arises when one attempts to summarize the effects of environmental regulations on factor flows, where literally hundreds of estimates have been published. Casual perusal of the literature indicates that construction of a consensus point estimate is akin to finding a needle in a haystack.

In this study we use a rigorous alternative to the casual narrative discussion of research studies by using a meta-analysis to examine statistically the impact of modeling approaches on empirical estimates presented in the literature. Using data from 11 empirical studies that supplied over 365 observations, we provide insights into possible explanations of the heterogeneous estimates reported in the literature. We find that regressors in each of four broad categories-empirical specification, data, environmental regulatory measure, and other control variables-have a degree of explanatory power in determining the magnitude and significance of the received estimates. With such information in hand, the more informed policymaker can better understand the limitations of simply relying on one parameter estimate when formulating policy. In addition, the theoretical or empirical researcher interested in specifying demand structures should also be interested in our findings because they highlight the degree to which elasticity estimates are sensitive to slight modeling changes. Finally, our results lend insight into future research that is necessary before any firm conclusions can be reached regarding the effects of environmental regulations on capital flows.

\section{REFERENCES}

Bartik, Timothy J. 1988. "The Effects of Environmental Regulation on Business Location in the United States," Growth and Change, 19, 22-44.

1989. "Small Business Start-Ups in the United States: Estimates of the Effects of Characteristics of States," Southern Economic Journal, 55, 1004-1018.

Becker, Randy and J. Vernon Henderson. 2000. "Effects of Air Quality Regulation On Polluting Industries," Journal of Political Economy, 108, 379-421.

Button, Kenneth J. 1995. "Evaluation of Transport Externalities: What Can We Learn Using Meta-analysis?" Regional Studies, 29, 507-517.

Button, Kenneth J. and John Kerr 1996. "Effectiveness of Traffic Restrain Policies: A Simple Meta-regression Analysis," International Journal of Transport Economics, 23, 213-225.

Cavlovic, Therese A., Kenneth H. Baker, Robert P. Berrens, and Kishore Gawande. 2000. "A Meta-Analysis of Environmental Kuznets Curve Studies," Agricultural and Resource Economics Review, 29, 32-42. 
Duerksen, Christopher J. 1983. Environmental Regulation of Industrial Plant Siting. Washington DC: The Conservation Foundation.

Duffy-Deno, Kevin. 1992. "Pollution Abatement Expenditures and Regional Manufacturing Activity," Journal of Regional Science, 32, 419-436.

Espey, Molly. 1998. "Gasoline Demand Revisited: An International Meta-analysis of Elasticities," Energy Economics, 20, 273-295.

Friedman, Joseph, Daniel A. Gerlowski, and Jonathan Silberman. 1992. "What Attracts Foreign Multinational Cooperations? Evidence From Branch Plant Location in the United States,” Journal of Regional Science, 32, 403-418.

Gerking, Shelby D. and List, John A. 2001. "Spatial Economic Aspects of the Environment and Environmental Policy," in H. Folmer, L. Gabel, S. Gerking, and A. Rose, (eds.), Frontiers of Environmental Economics, Cheltenham, U.K.: Edward Elgar.

Goodstein, Eban. 1999. The Trade-off Myth: Fact and Fiction About Jobs and the Environment, Washington, DC: Island Press.

Gray, Wayne B. 1997. "Manufacturing Plant Location: Does State Pollution Regulation Matter?" Clark University.

Henderson, J. Vernon. 1996. "Effects of Air Quality Regulation,” American Economic Review, 86, 789-813.

- 1997. "The Impact of Air Quality Regulation on Industrial Location,” Annales D'Economie Et De Statistique, 45,123-137.

Howenstine, Ned G. and William J. Zeile. 1994. "Characteristics of Foreign-Owned U.S. Manufacturing Establishments," Survey of Current Business, January.

Jaffe, Adam B., Steven R. Peterson, Paul R. Portney, and Robert N. Stavins. 1995. "Environmental Regulation and the Competitiveness of U.S. Manufacturing: What Does the Evidence Tell Us?" Journal of Economic Literature, XXXIII, 132-163.

Jeppesen, Tim and Henk Folmer. 2002. "The Confusing Relationship Between Environmental Policy and Location Behaviour of Firms: A Methodological Review of Selected Case Studies," The Annuals of Regional Science.

Kahn, Matthew. E. 1997. "Particulate Pollution Trends in the United States," Regional Science and Urban Economics, 27, 87-107.

Keller, Wolfgang and Arik Levinson 1999. "Environmental Regulations and FDI Inflows to U.S. States: The Potential for a 'Race to the Bottom' of Environmental Stringency,” Paper prepared for the ISIT99 Conference, June 4-5.

Leamer, Edward. E. 1983. "Let's Take the Con Out of Econometrics," American Economic Review, 73, 31-43.

Levinson, Arik. 1996 "Environmental Regulations and Manufacturer's Location Choices: Evidence from the Census of Manufactures," Journal of Public Economics, 61, 5-29.

List, John A. 2001. "U.S. County-Level Determinants of Inbound FDI: Evidence from a Two-Step Modified Count Data Model," International Journal of Industrial Organization, 19, 953-973.

List, John A. and Catherine Co. 2000. "The Effects of Environmental Regulations on Foreign Direct Investment," Journal of Environmental Economics and Management, 40, 1-20.

List, John A. and Craig Gallet. 2000. "What Experimental Protocol Influence Disparities Between Actual and Hypothetical Stated Values? Evidence from a Meta-Analysis,” Environmental and Resource Economics.

List, John A. and Shelby Gerking. 2000. "Regulatory Federalism and U.S. Environmental Policies," Journal of Regional Science, 40, 453-471.

List, John A. and Mitch Kunce. 2000. "Environmental Protection and Economic Growth: What do the Residuals Tell Us?” Land Economics, 76, 267-282.

List, John A. and Charles F. Mason. 2001. "Optimal Institutional Arrangements for Pollution Control: Evidence from a Differential Game with Asymmetric Players,” Journal of Environmental Economics and Management, forthcoming.

List, John A., Warren McHone, Junsoo Lee, and Mark Soskin. 1999. "Effects of Air Quality Regulation on Manufacturing Births: Evidence from a Panel of Counties in New York State," working paper AREC, University of Maryland.

(C) Blackwell Publishing, Inc. 2002. 
McConnell, Virginia D. and Robert M. Schwab. 1990. "The Impact of Environmental Regulation on Industry Location Decisions: The Motor Vehicle Industry," Land Economics, 66, 67-81.

Rauscher, Michael. 1994. “On Ecological Dumping,” Oxford Economic Papers, 46, 822-840.

- 1997. International Trade, Factor Movements and the Environment. Oxford: Oxford University Press.

Smith, V. Kerry and Ju-Chin Huang. 1993 "Hedonic Models and Air Pollution: Twenty-Five Years and Counting," Environmental and Resource Economics, 3, 381-394.

—. 1995. "Can Markets Value Air Quality? A Meta-Analysis of Hedonic Property Value Models," Journal of Political Economy, 103, 209-227.

Smith, V. Kerry and Yoshiaki Kaoru. 1990. "Signals or Noise? Explaining the Variation in Recreation Benefit Estimates," American Journal of Agricultural Economics, 72, 419-433.

Stanley, T. D. 1998. "New Wine in Old Bottles: A Meta-Analysis of Ricardian Equivalence," Southern Economic Journal, 64, 713-727.

Tannenwald, Robert. 1997. "State Regulation Policy and Economic Development," New England Economic Review, Proceedings of a Symposium on the Effects of State and Local Public Policies on Economic Development. March/April, pp. 83-97.

Ulph, Alistair. 1997. "International Trade and the Environment," In H. Folmer and T. Tietenberg (eds.), The International Yearbook of Environmental and Resource Economics 1997-98. Survey of Current Issues. Cheltenham: Edward Elgar, pp. 205-242.

U.S. Department of Commerce. 1994. Current Industrial Reports. Pollution Abatement Costs and Expenditures: 1994. Washington DC: Bureau of the Census.

van den Bergh, Jeroen C. J. M, and Kenneth J. Button. 1997. "Meta-analysis of Environmental Issues in Regional, Urban and Transport Economics," Urban Studies 34, 927-944.

Wasylenko, Michael. 1997. "Taxation and Economics Development: The State of the Economic Literature," New England Economic Review, Proceedings of a Symposium on the Effects of State and Local Public Policies on Economic Development. March/April, pp. 83-97.

Wilson, John Douglas. 1996. "Capital Mobility and Environmental Standards: Is There a Theoretical Basis For a Race to the Bottom," in J. Bhagwati and R.P. Hudec (eds.), Fair Trade and Harmonization: Prerequisites for Free Trade, Volume 1. Cambridge: MIT Press, pp. 393-427. 


\section{APPENDIX}

TABLE A1: Papers Included in the Meta-Analysis*

\begin{tabular}{|c|c|c|c|c|}
\hline Author/Dependent Variable & Data Set & Measures of Regulatory Stringency & Estimation Procedure & Results \\
\hline $\begin{array}{l}\text { Bartik (1988) } \\
\text { New branch plant location. }\end{array}$ & $\begin{array}{l}\text { New manufacturing } \\
\text { branch plants opened by } \\
\text { the Fortune } 500 \text { compa- } \\
\text { nies between } 1972 \text { and } \\
1978 . \text { Obtained from the } \\
\text { Dun and Bradstreet Cor- } \\
\text { poration, corrected by } \\
\text { Schmenner (1982). }\end{array}$ & $\begin{array}{l}\text { The average of } 1972-1978 \text { state govern- } \\
\text { mental spending on water quality control } \\
\text { divided by manufacturing employment. } \\
\text { The average of } 1972-1978 \text { state govern- } \\
\text { mental spending on air quality control } \\
\text { divided by manufacturing employment. } \\
\text { State water pollution compliance costs } \\
\text { divided by expected water pollution com- } \\
\text { pliance costs, given state industry mix, } \\
\text { 1978. } \\
\text { State air pollution compliance costs } \\
\text { divided by expected air pollution compli- } \\
\text { ance costs, given state industry mix, } 1978 \text {. } \\
\text { Percentage reduction in particulate emis- } \\
\text { sions from industrial boilers required by } \\
\text { state regulations. } \\
\text { Percentage reduction in particulate emis- } \\
\text { sions from industrial boilers required by } \\
\text { state regulations, adjusted for state-wide } \\
\text { fuel mix. }\end{array}$ & Conditional Logit. & $\begin{array}{l}\text { None of the coefficients } \\
\text { on measures of regula- } \\
\text { tory stringency are sig- } \\
\text { nificant. Coefficients } \\
\text { generally have a posi- } \\
\text { tive sign. }\end{array}$ \\
\hline
\end{tabular}

* Extended and elaborated version of the appendix table in Tannenwald, 1997. 


\begin{tabular}{|c|c|c|c|c|}
\hline Author/Dependent Variable & Data Set & Measures of Regulatory Stringency & Estimation Procedure & Results \\
\hline $\begin{array}{l}\text { Becker and Henderson } \\
(2000) \\
\text { Firm births. }\end{array}$ & $\begin{array}{l}\text { Plant and industry Data } \\
\text { come from the Longitudi- } \\
\text { nal Research Database } \\
\text { (LRD) based on the U.S. } \\
\text { Census of Manufactur- } \\
\text { ers, 1963, 67, 72, 77, } 82 \text {, } \\
87 \text {,and } 92 \text {. Five sectors } \\
\text { are included: (1) indus- } \\
\text { trial organic chemicals, } \\
\text { (2) miscellaneous plastic } \\
\text { products, (3) metal cans } \\
\text { and barrels , (4) wood } \\
\text { furniture, and (5) com- } \\
\text { mercial printing. }\end{array}$ & $\begin{array}{l}\text { Attainment status: A dichotomous vari- } \\
\text { able that is equal to unity if the county is } \\
\text { out of attainment of the primary federal } \\
\text { standard for ozone, and zero otherwise. }\end{array}$ & $\begin{array}{l}\text { Conditional Poisson. } \\
\text { Fixed effects. }\end{array}$ & $\begin{array}{l}\text { Air quality regulations } \\
\text { reduced the number of } \\
\text { births dramatically in } \\
\text { nonattainment coun- } \\
\text { ties, compared to at- } \\
\text { tainment counties. } \\
\text { This shift in birth pat- } \\
\text { terns induces a reallo- } \\
\text { cation of stocks of } \\
\text { plants toward attain- } \\
\text { ment counties. In the } \\
\text { later years of regula- } \\
\text { tion non-attainment } \\
\text { status reduces ex- } \\
\text { pected births by 40-50 } \\
\text { percent. In the 1970s, } \\
\text { significant effects ap- } \\
\text { pear for large plants. } \\
\text { In later periods, effects } \\
\text { appear for many types } \\
\text { of firms - but corporate } \\
\text { plants are much more } \\
\text { influenced relative to } \\
\text { the much smaller non- } \\
\text { affiliate, or single } \\
\text { plant firms. }\end{array}$ \\
\hline
\end{tabular}




Author/Dependent Variable Data Set $\quad$ Measures of Regulatory Stringency

Data on new manufac-

turing plant openings

'Green policies' index based on GREEN.

Measures public pollution abatement

Gray (1997)

Numbers of new plants.

comes from the Longitu-

efforts such as the presence of specific

dinal Research Database laws.

LRD) based on the U.S.

Census of Manufactur-

ers, 1963, 67, 72, 77, 82,

and 89. Data on each

state are aggregated to

get the total number of

openings at five-year

'Green Conditions' index based on

GREEN. Measures the quality of the states' environment.

Number of inspections of manufacturing plants between 1984 and 1987, divided by the number of manufacturing plants in 1982 .

State spending (\$ per capita) on programs for environmental and natural resources in 1988.

Pollution abatement operating costs

calculated as actual pollution abatement expenditures (taken from PACE) relative

to predicted abatement expenditures.

Percent of population who are members of a 'conservation' group.

The average score for each states' member of Congress on environmental issues. $\mathrm{Ob}$ tained from the League of Conservation Voters.

Estimation Procedure Results

OLS.

Fixed effects model.

Random effects model.

Conditional logit.

Poisson.

Some of the measures of regulatory stringency are negative and statistically signifi-

cant. Which measures depend on estimation procedure.

Results for highpollution industries are not more significant than the results for all manufacturing industries. 
State pollution abatement costs from the 1) Investments by foreign-owned manufacturers and manufacturing employees working for foreign-owned firms. Obtained form the Bureau of Economic Analysis (BEA)

2) Planned new factory expenditures by foreignowned firms, using count data models of investment decisions. Obtained from the

International Trade

Administration (ITA)

Data are reported for the chemical industry (1977-1991) and for manufacturing (1977-1994).
Measures of Regulatory Stringency PACE data set, adjusted using each state' industrial composition. The index compares the actual abatement costs in each

Estimation Procedure Results

OLS.

Fixed-effects.

Pooled Poisson

por industrial composition, to the predicted abatement costs in each state, where predictions are based solely on nationwide abatement expenditures by industry and each state's industrial composition.

Fixed-effects Poisson.

Generalized Method of Moments

\section{Unadjusted index from the PACE data.}

The average score for each state's member of Congress on environmental issues. Obtained from the League of Conservation Voters.
FDI and the industryadjusted index are statistically significant and negatively correlated only for the chemical sector and only in the fixedeffects model.

Coefficients of the unadjusted index are less statistically significant.

FDI and the League of Conservation Voters index are significant and negatively correlated only for manufacturing, and only in the fixed-effects model.

Coefficients of regulatory stringency measures are generally insignificant when new plants are the dependent variable. 
Measures of Regulatory Stringency

A set of 994 individual manufacturing plants

that opened in New Yor

State during the period 1980-1990.

This database was constructed from the Industrial Migration File, maintained by the New York State Department of Economic Development.

Data are analysed for all manufacturing industries together as well as separately for two subsamples-a pollution intensive subsample (SIC26, 28, 29, $32,33,34$, and 37) and a non-pollution intensive subsample (the re-

maining industries in manufacturing).
Attainment status: a county is designated as either in attainment or out of attain-

ment of primary national air quality standards in each of the years in the period 1980-1990. This variable takes the value 1 if a county is out of attainment in a given year, and 0 if the county is in attainment.

The sample is split into a 'neo-regulatory' period (1980-1984), and a 'mature regulatory' period (1985-1990).
Estimation Procedure

Poisson. \\ Poisson.}

Results

The pooled models indicate that the plant location decision is largely unrelated to county attainment status in both regulatory eras.

For the pollution intensive firms, the coefficient of the attain ment status variable is significant and negative in the 'mature regulatory' period. When a county is labelled out-of-

attainment, its flow of births decreased by around $90 \%$ between 1985-1990.

For the non-pollution intensive firms, the coefficient of the attainment status variable is sig-

nificant and positive in the 'neo regulatory' period. When a county is labeled out-ofattainment its flow of births increased by around $40 \%$ between 1980-1984. 


Author/Dependent Variable
McConnell and Schwab
(1990)
New plant location.

Data Set

Measures of Regulatory Stringency

Estimation Procedure

Results

Start-up plants in SIC

Nonattainment: Dummy variable equal

Conditional logit.

Only the coefficient on

industry 3711 (automo- to 1 if county had not attained the ozone

bile assembly and emis- standard in 1977, 0 otherwise.

sions) in 1973,1975 ,

1979 , and 1982 as re-

ported by Dun and

Nonattain82: Dummy variable equal to 1 if

county had not attained the ozone stand-

Bradstreet, corrected by

follow-up telephone calls. ard in either 1977 or 1982,0 otherwise.

Extended: Nonattain82 multiplied by a dummy variable equal to 1 if a county either (a) had requested an extension to 1987 to meet the ozone standard, or

(b) was subject to a 'State Implementation Plan call', 0 otherwise.

Ozone: Nonattain 82 multiplied by ozone concentration at highest meter (2nd highest reading in the county, 1977-79).

Days: Nonattain 82 multiplied by the number of days per year highest meter in county was out of compliance, 1977-79.

Opcost: State pollution abatement operating costs in industry 37 as a proportion of state value of shipments in industry 37 .

Topreg: Permitted lbs of VOC/gallon of solvent excluding water in industry 3711, 1982-83.

Pace: State total abatement capital expenditures as a proportion of new capital expenditures in all manufacturing industries, 1977.

Fees: Dummy variable equal to 1 if state set fees for operating and construction permits as of 1978,0 otherwise. 